\title{
The Spatial Distribution of Public Dispensaries in the City of Jeddah (Kingdom of Saudi Arabia)
}

\author{
Mongi Belarem*, Mohamed Hafedh Hamza, Mohamed Ajmi \\ Department of Geography and Geographic Information Systems, Faculty of Arts and Humanities, King Abdulaziz University, \\ Jeddah, KSA \\ Email: *aremmongi@yahoo.fr
}

How to cite this paper: Belarem, M. Hamza, M.H. and Ajmi, M. (2020) The Spatial Distribution of Public Dispensaries in the City of Jeddah (Kingdom of Saudi Arabia. Open Access Library Journal, 7: e6194.

https://doi.org/10.4236/oalib.1106194

Received: February 27, 2020

Accepted: April 4, 2020

Published: April 7, 2020

Copyright ( $\odot 2020$ by author(s) and Open Access Library Inc.

This work is licensed under the Creative Commons Attribution International License (CC BY 4.0).

http://creativecommons.org/licenses/by/4.0/

\section{Open Access}

\begin{abstract}
In Saudi Arabia, access to healthcare is considered as a human right for citizens and residents. Admittedly, there are spatial inequalities in access to care services between the inhabitants of cities and those of rural areas of the Kingdom. In the urban area of Jeddah, and like other Saudi urban areas, the distribution of healthcare equipment, and especially of basic state health centers (dispensaries), is very uneven. However, very few studies have been produced in this context. In this work, we have tried to map and analyze the spatial inequalities in the distribution of public dispensaries in Jeddah and the levels of access of inhabitants to these dispensaries. The main objectives of this study are as follows: Assess the population's access to public dispensaries by crossing the population map with that of public dispensaries and by some other spatial analyzes such as the analysis of the supply of healthcare by neighborhood through public dispensaries, as well as the comparison of the situation of the various districts in terms of health care, through access to these dispensaries; finally, help decision-making by proposing alternatives to ensure fairness in access to medical care. This study proposes to assess levels of access to public dispensaries in Jeddah through the following steps: First, we presented the methodology adopted in this study as well as the study area. Next, we showed the spatial distribution of dispensaries and the population's levels of access to healthcare. Finally, we presented some alternatives to help decision-makers to improve the conditions of accessibility to health facilities for the inhabitants. The obtained results show large spatial disparities in accessibility to healthcare and a local spatial relationship between accessibility and population concentration. This relationship results in an opposition between the North and the South of the city on the one hand, where we note that the level of accessibility is low with a low concentration of the population, and the central area on the other hand, which is characterized by a high population density and a relatively high level of accessibility.
\end{abstract}




\section{Subject Areas}

Human Geography

\section{Keywords}

Accessibility, Spatial Disparity, Public Dispensaries, Jeddah

\section{Introduction}

In the city of Jeddah and like other Saudi cities, there are spatial inequalities of access for inhabitants to health care services. Indeed, the distribution of healthcare equipment, and especially public dispensaries, is very uneven. However, in this context, very few reports and studies have been produced.

Through this study, we will try to map and analyze the spatial inequalities in the distribution of public dispensaries in Jeddah and the levels of access of inhabitants to these dispensaries. We will establish the map of the distribution of public dispensaries and superimposed it with that of the population using the dot density method, to verify the degree of proximity of public dispensaries to inhabitants.

This work required the collection of a large mass of data relating to health facilities and to the spatial distribution of inhabitants. We will correlate the spatial distribution of the population with that of public dispensaries to determine the size of the advantaged population and the size of the unfavorable one in terms of proximity to dispensaries.

We will finish this study through the following axes: First, we will present the methodology adopted in this work as well as the study area. Next, we will show the spatial distribution of public dispensaries and the population's levels of access to healthcare. Finally, we will present some alternatives to help decision-makers to improve the conditions of accessibility to health facilities for inhabitants.

\section{Study Area and Problematic}

The study area is the city of Jeddah. It is the second city in Saudi Arabia after the capital Al-Riadh, with nearly 3.5 million inhabitants. It currently covers almost $5000 \mathrm{~km}^{2}$ on which almost $1000 \mathrm{~km}^{2}$ are fully urbanized [1]. We will limit this study to the urban area which is subdivided into 95 districts (Figure 1).

The work issue revolves around the assessment of spatial disparities in the accessibility of inhabitants to public dispensaries in this city. Private dispensaries were excluded from this study because few people, especially those who can afford it, can access them. Hospitals have also been excluded, as they receive only referred cases. In addition, they constitute regional and national structures whose level of attraction greatly exceeds the local scale that interests us [2]. 

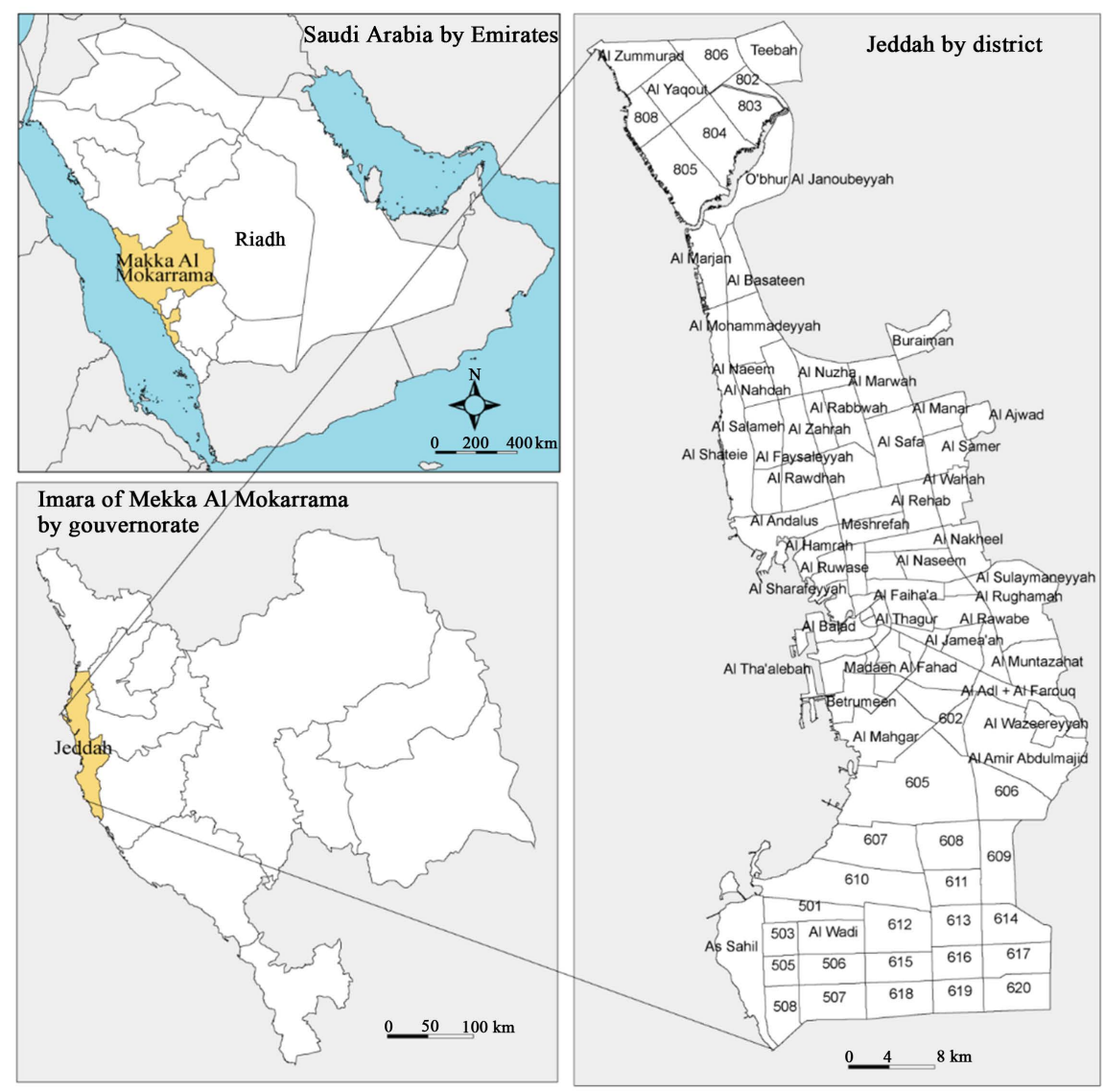

Figure 1. Study area (Belarem et al., 2018).

\section{Methodology}

In the health sector, there are several methods and several indicators for evaluating the services presented to residents. The methodology followed to develop this work concerns two elements; a theoretical one and another practical. It concerns the criteria for measuring accessibility, and subsequently the cartographic work which relates the distribution of dispensaries with that of the population. In health geography, geographic accessibility is the material capacity to access health services [2] [3] [4].

For the criteria of geographic accessibility to dispensaries, there are several methods to address this issue, among these methods, we can cite the distance between residents and health care centers [3] [5] [6] [7] [8], the density of health care offers within the administrative unit [2] [9], the number of visits and the gravity model [10] [11]. Penchansky and Thomas have also studied the concept of access to health care [12] [13]. They define five components (sub-concepts) associated with the concept of access to care, which are availability, accessibility, convenience, financial capacity and acceptability [14]. Access to basic health care centers therefore defines a good indicator of the accessibility of inhabitants to healthcare. A range of health care services must be available at a reasonable distance for the people who need it [15]. For this reason, and in the absence of detailed data relating to the equipment, personnel and number of visits for each 
dispensary, we take here the distance, which separates the inhabitant at the nearest dispensary, as the main criterion to assess accessibility [11] [14] [15].

As for cartographic work, a very important element for the visualization of the accessibility issue, we superimposed the layer of dispensaries with the population map. We mainly used the dot density map. We did this based on the $1 / 25,000$ topographic map of Jeddah, a satellite image (SPOT 5) covering the study area, thematic maps, Google Earth, and our knowledge of the terrain. The dot density map (Figure 2) gives an idea closer to reality, especially by comparing it with that of proportional circles (Figure 3 ).

\section{Data and Software Used}

To do this work, we used two types of data from different sources. Data relating to health comes from the Saudi Ministry of Health (https://www.moh.gov.sa) [16], the Jeddah Public Health Administration and the municipality of Jeddah (https://www.jeddah.gov.sa) [17]. The population data come from the Saudian General Authority for Statistics (https://www.stats.gov.sa) [18] and the municipality of Jeddah (https://www.jeddah.gov.sa) [17]. We also extracted some data from several previous studies [1] [2] [19]-[26]. The maps were extracted from the Atlas of the local plan for the city of Jeddah

(https://www.jeddah.gov.sa/Business/LocalPlanning/Atlas/index.php) [27] and

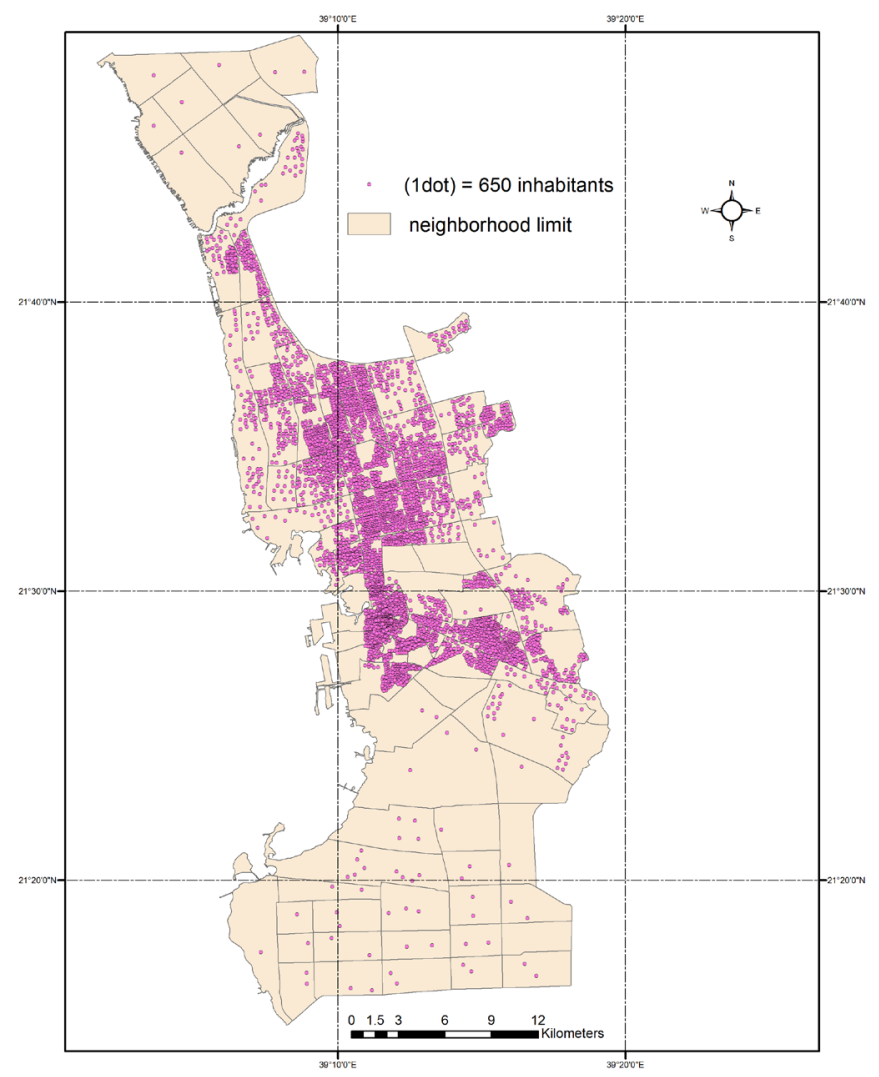

Figure 2. Distribution of the population by district in Jeddah (Dot density method) (Source: Belarem et al., 2018). 


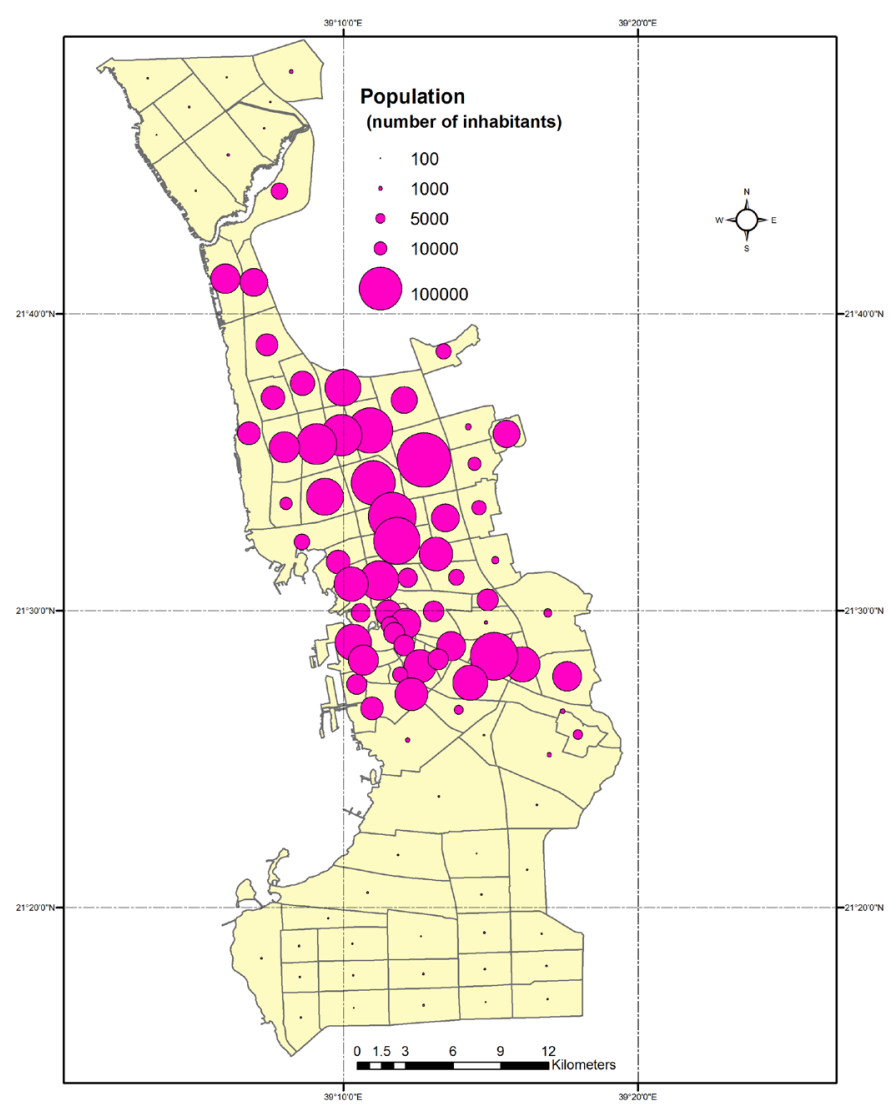

Figure 3. Distribution of the population by district in Jeddah (Proportional circles method) (Source: Belarem et al., 2018).

the Saudi Geological Survey (https://sgs.org.sa) [28]. Topographic maps and Satellite image (Spot 5, year 2010) updated using Google Maps, were used to create thematic maps including those of the dispensaries.

In the present study, we used ArcGis software to build a health database that focuses on public dispensaries. We also used Microsoft Excel to organize the statistical data as well as for the creation of some graphs.

\section{Diagnosis of the Current Situation of Public Dispensaries}

\subsection{Distribution of Public Dispensaries in the Region of Makkah}

At national scale, there are 2325 public dispensaries. They left very unevenly between the regions and governorates. Figure 4 shows that nationwide, Makkah province ranks third with 331 clinics after Al-Riadh (with 424 clinics) and Aseer (with 334 clinics).

In 2016, in the governorate of Jeddah, there are 13 hospitals, with a capacity of 3091 beds (https://www.moh.gov.sa) which are spread over several cities (Figure 5). The largest number of hospitals is in the city of Jeddah.

A large part of these establishments exist in urban space. In fact, there are 491 healthcare establishments, 10 public hospitals including 4 regional hospitals, 40 private hospitals and 47 dispensaries (Table 1 and Figure 6). 


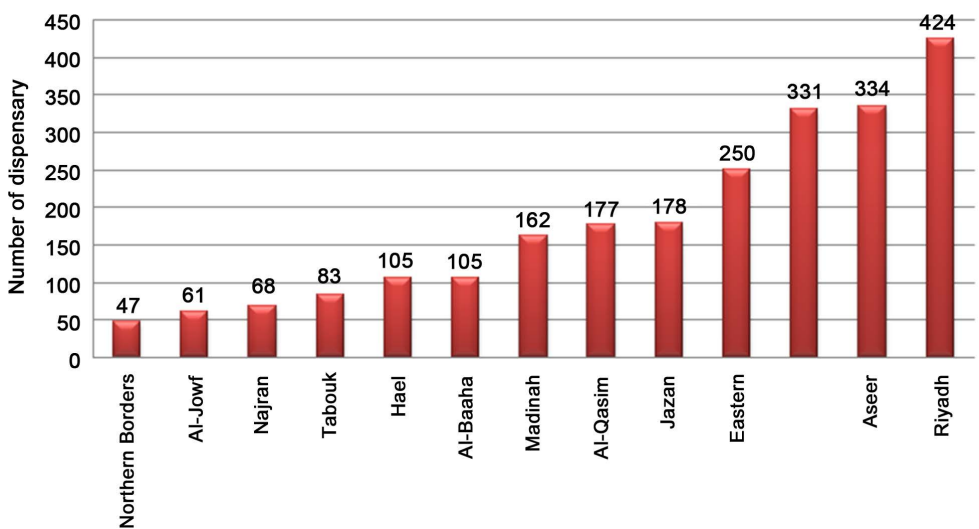

Figure 4. Distribution of public dispensaries in Saudi Arabia according to the provinces in 2016 (Source: https://www.stats.gov.sa).

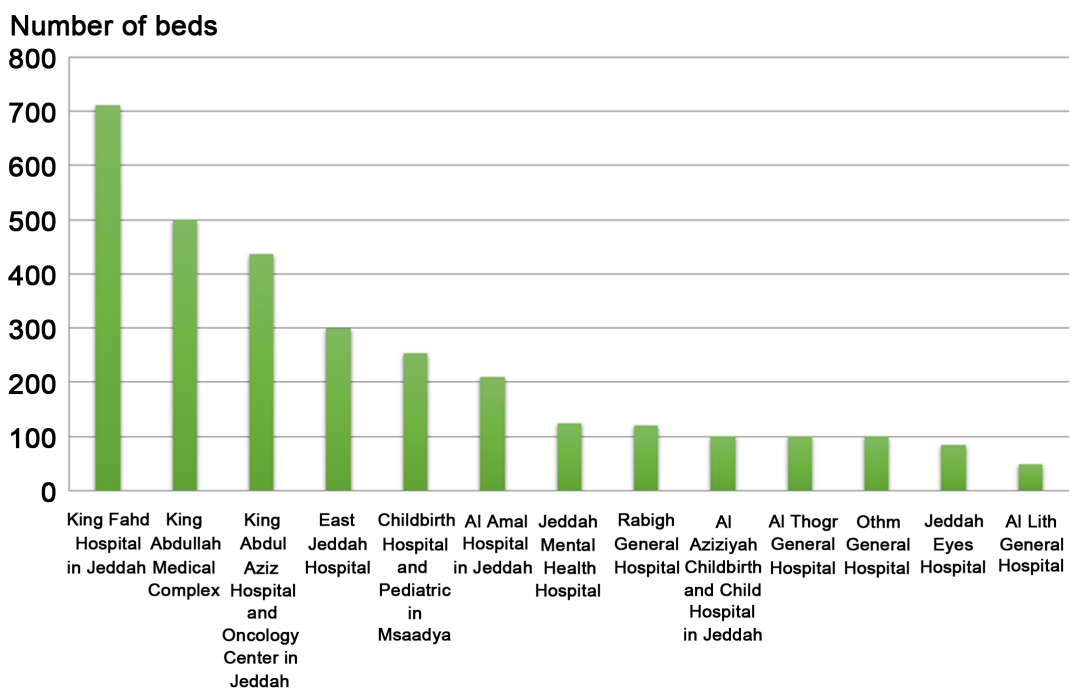

Figure 5. Distribution of public hospitals in Jeddah province and their capacities in 2016 (Source: https://www.moh.gov.sa).

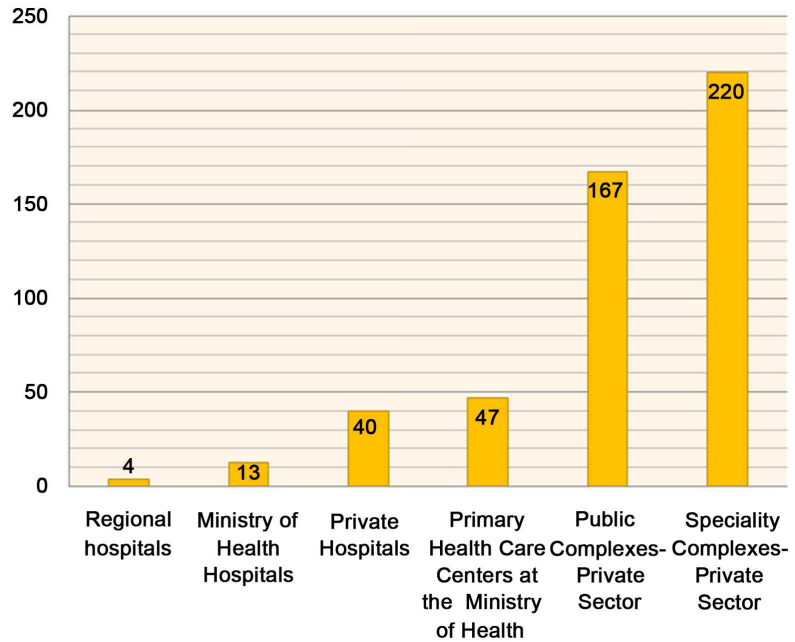

Figure 6. Distribution of health facilities in Jeddah in 2016. (Data source: https://www.moh.gov.sa). 
Table 1. Breakdown of healthcare facilities in Jeddah in 2016 (https://www.moh.gov.sa).

\begin{tabular}{cc}
\hline Establishment & Number \\
\hline Regional public hospitals & 4 \\
Public hospitals & 13 \\
Private hospitals & 40 \\
Public dispensaries & 47 \\
Complexes-Private Sector & 167 \\
Specialty Complexes-Private Sector & 220 \\
\hline
\end{tabular}

Figure 5 shows that the total number of beds in hospitals is 3091. The distribution of beds is very uneven among institutions. The three hospitals of King Fahd, King Abdullah and King Abdul Aziz occupy 53.28\% of all beds. The King Fahd hospital monopolizes only $23 \%$ of the total reception capacity. However, 6 hospitals comprise only $17.96 \%$ of the total beds. This centralization of capacity has a bad impact on patients. People sometimes travel long distances to get care service. The authorities must therefore review the distribution situation of health establishments by setting up other health establishments in the least equipped areas.

The city of Jeddah therefore defines a large health center in Saudi Arabia. It alone comprises $14.19 \%$ of the public dispensaries of the province of Makkah. In addition to these establishments, there is a large network of private dispensaries and other public and private specialized health centers. By comparing the proportion of public dispensaries to the number of population, we can notice that this proportion is relatively small, for example, there are only 47 public dispensaries for nearly 3.5 million inhabitants (1 dispensary for each 74,500 inhabitants).

\subsection{Accessibility of Residents to Dispensaries in the City of Jeddah}

In the urban space of Jeddah which is subdivided into 95 districts, there are 29 districts in which there public dispensaries, while 66 districts lack these facilities (Figure 7).

The levels of inequalities in access to care vary between different areas of the city (North, Center and South) and from one district to another. These are generally the most populated areas in which the clinics are found. These are the most populated areas where the dispensaries are located. However, there are nine densely populated districts that do not have a public health center (Figure 7). Access to public dispensaries is very poor in the south and north of the city, and is relatively acceptable in the central area. By examining the two Figure 8 and Figure 9, one can distinguish between three zones, a central zone in which there are almost all the public dispensaries, and two other zones; a northern zone in which there is no state dispensary and another in the south which contains only one dispensary. 


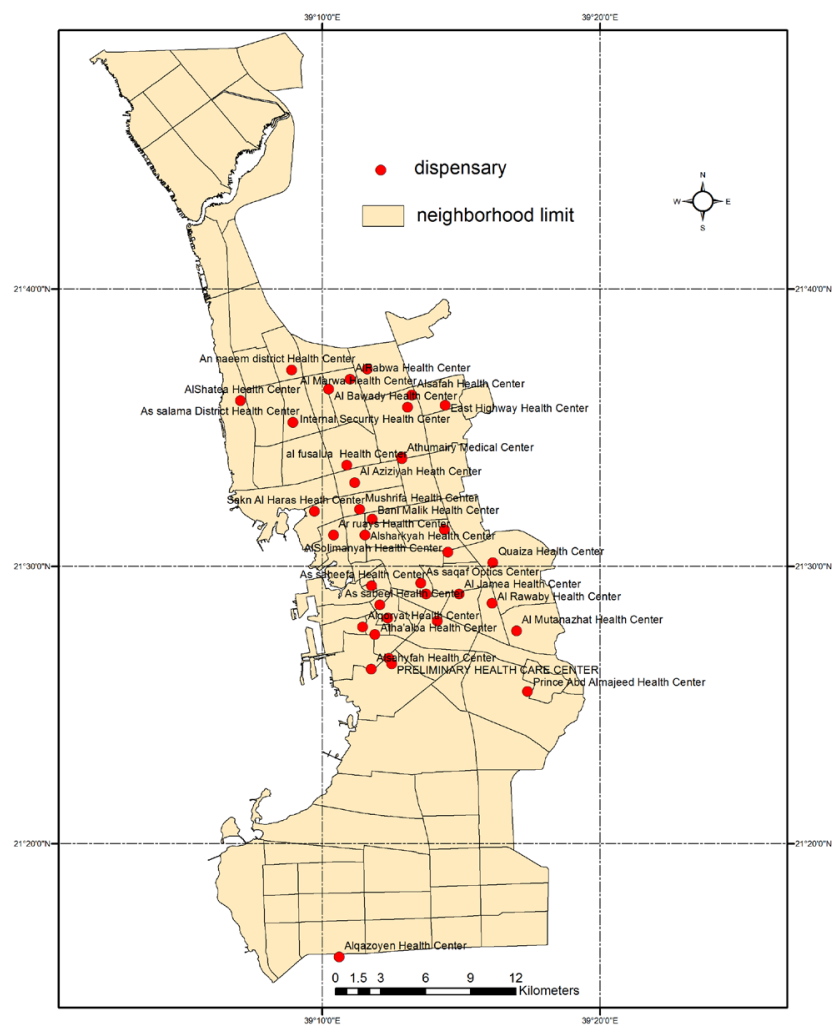

Figure 7. Districts of Jeddah (with or without dispensaries).

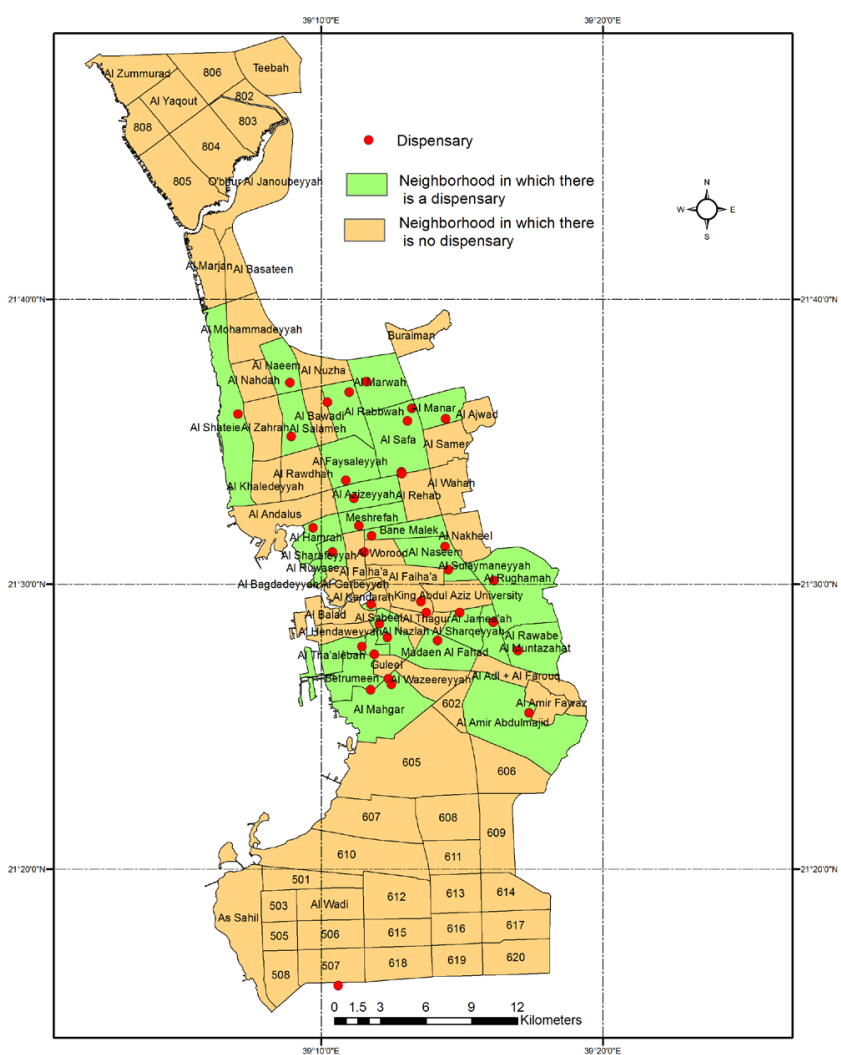

Figure 8. Spatial distribution of public dispensaries in Jeddah. 


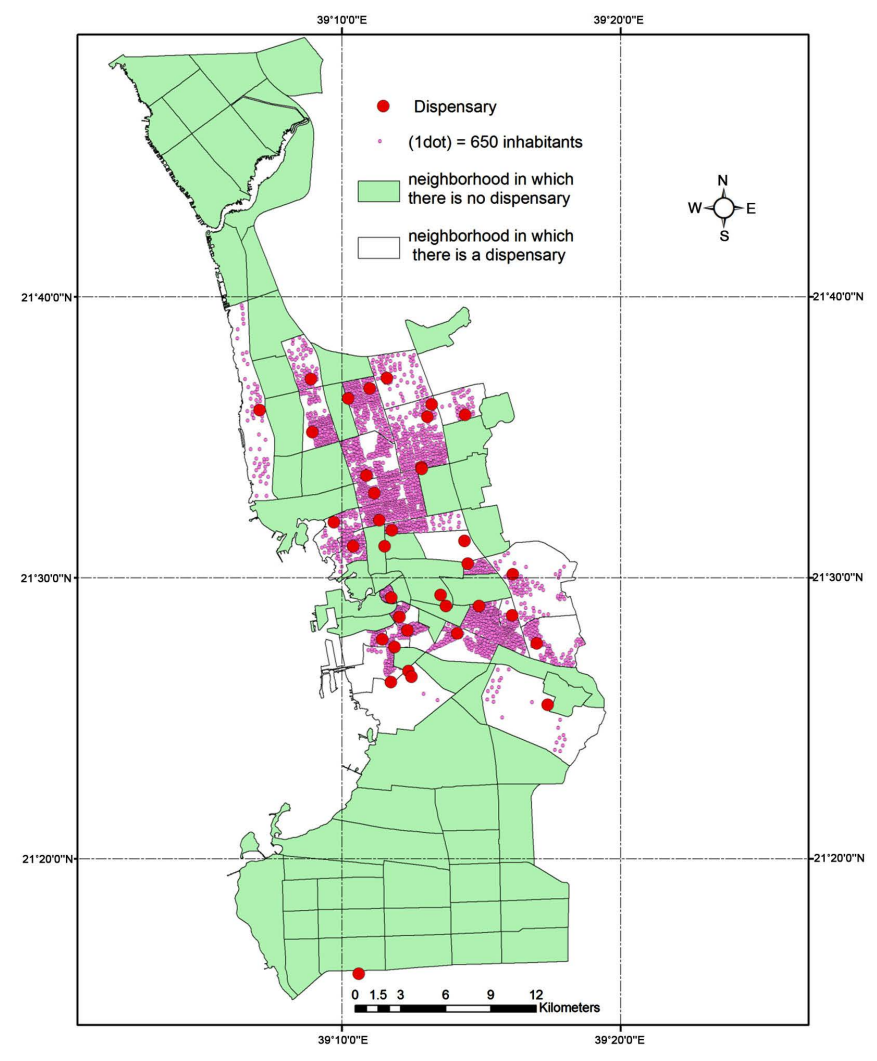

Figure 9. Population of neighborhoods in which there are dispensaries.

Figure 10 shows that $1,427,400$ residents live in neighborhoods where there is no public dispensaries ( $41 \%$ of the total population of the urban area). These people move to access dispensaries closest to their neighborhoods. Figure 11 shows that 468,000 inhabitants are less than 500 meters from a public dispensary, while the rest of the residents live more than 500 meters from (Figure 12). The existing population at a distance of less than $2 \mathrm{~km}$ from a dispensary is estimated at 2,834,650 inhabitants (Figure 13). Figure 14 shows the size of the population separated by more than $2 \mathrm{~km}$ from a public dispensary, i.e. around 623,144 inhabitants. The population located more than $5 \mathrm{~km}$ from a dispensary is estimated at 192,400 inhabitants, or approximately $5.6 \%$ of the total population.

The main importance of this research is that it has linked the spatial distribution of state clinics with that of the population. It showed the poor distribution of state dispensaries, between privileged and other disadvantaged neighborhoods. In this context, the authorities must help to resolve this situation with the creation of new dispensaries in the least equipped neighborhoods, that is to say in the northern and southern districts of the city.

This project was funded by the Dean of Scientific Research (DSR) at King Abdulaziz University, Jeddah, Kingdom of Saudi Arabia, under grant Number G-263-125-1440. We have thus helped to reveal the spatial inequalities in access to healthcare at state dispensaries in the city of Jaddah. The lack of public 


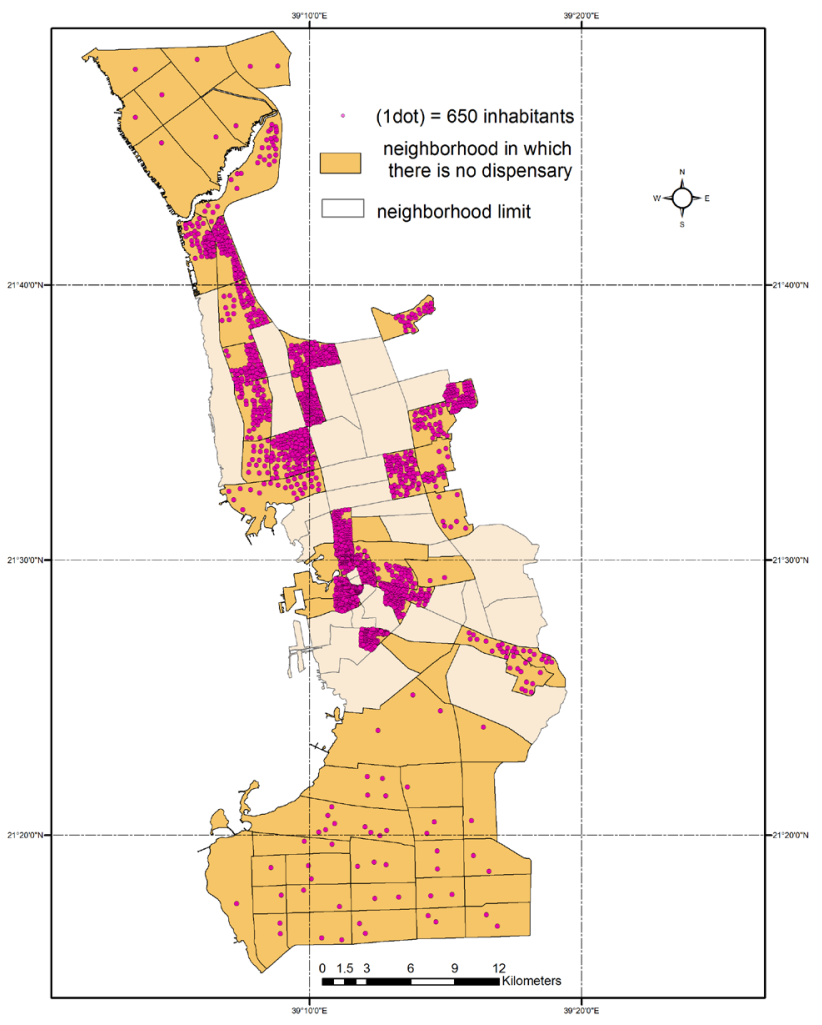

Figure 10. Population of neighborhoods in which there is no dispensary.

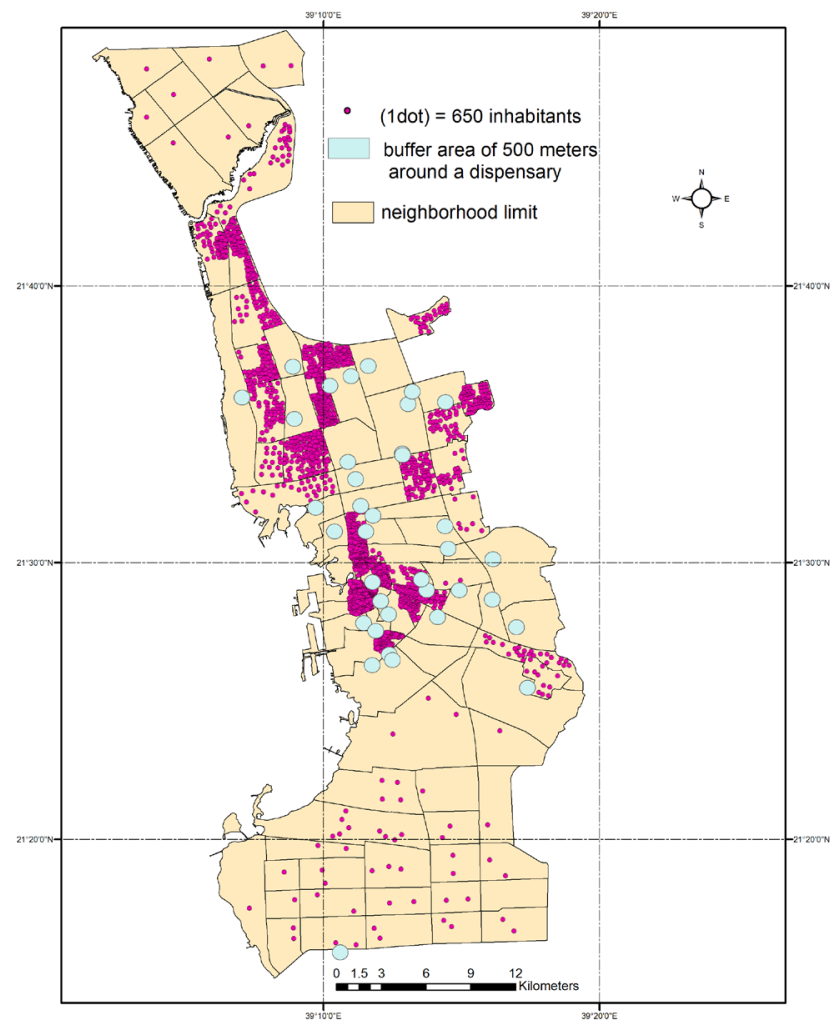

Figure 11. Distribution of the population at a distance greater than 500 $\mathrm{m}$ from a public dispensary. 


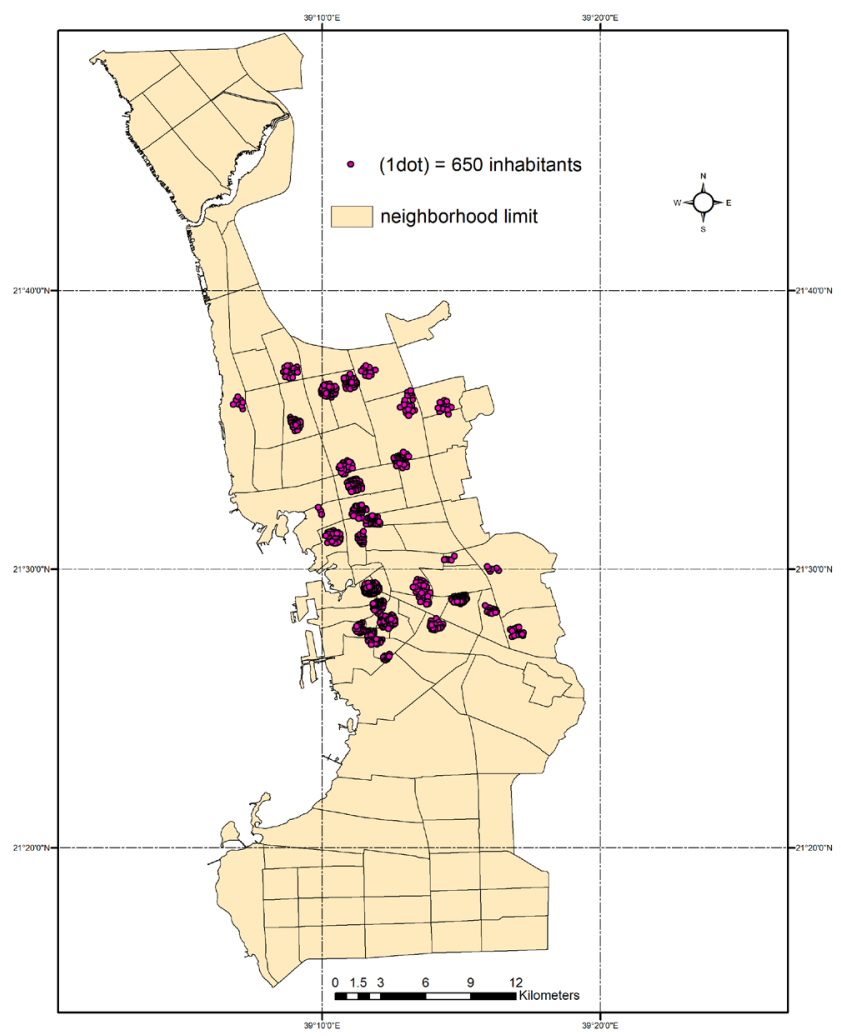

Figure 12. Distribution of the population at a distance of less than $500 \mathrm{~m}$ from a public dispensary.

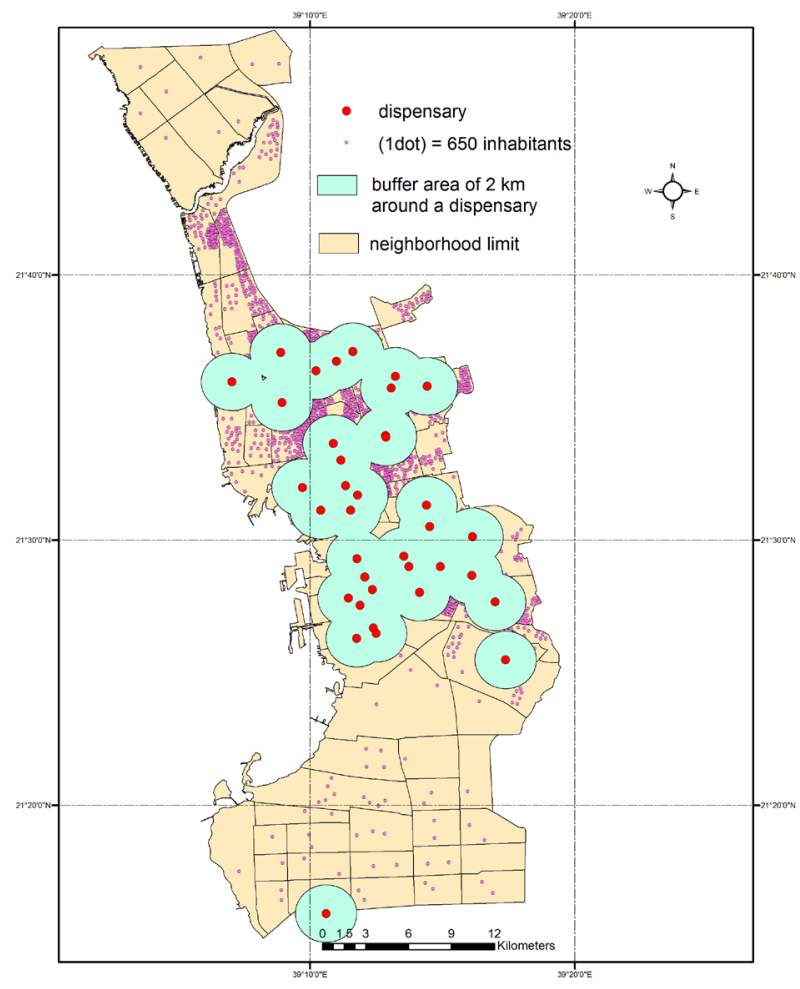

Figure 13. Distribution of the population that exists at a distance less than 2 $\mathrm{km}$ from a public dispensary. 


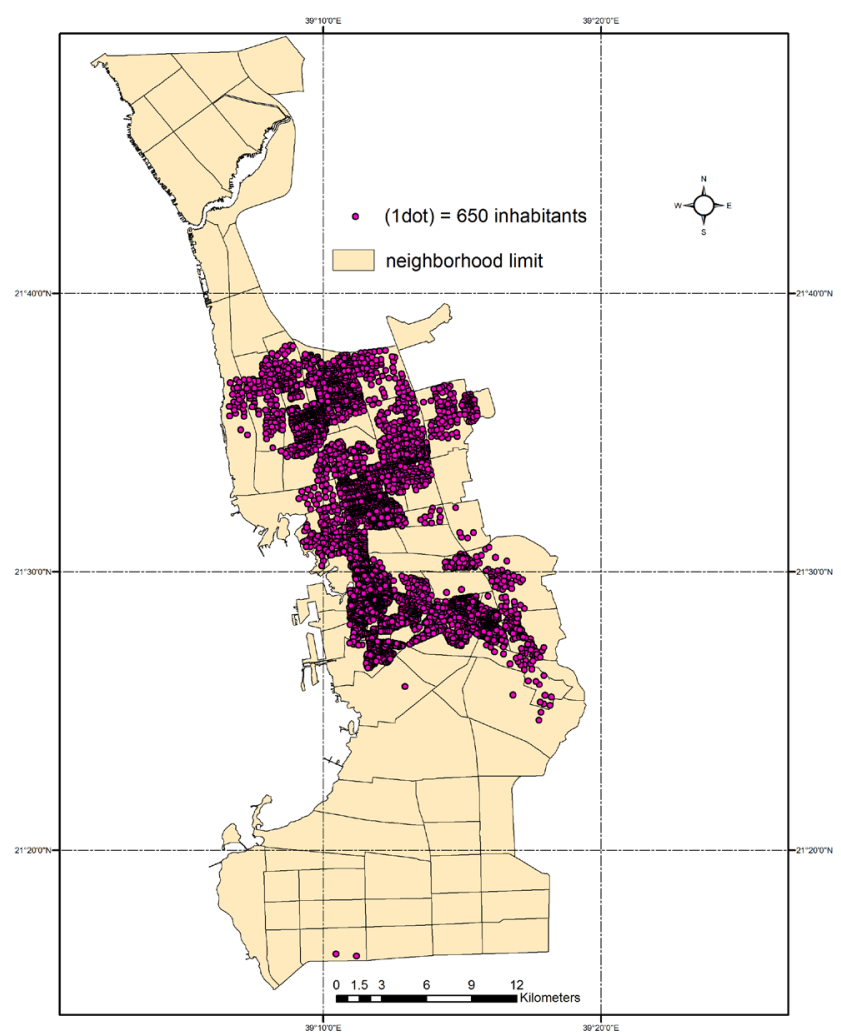

Figure 14. Distribution of the population that exists at a distance greater than $2 \mathrm{~km}$ from a public dispensary.

transport makes commuting difficult for people without a private car. The authorities must therefore put in place a fair and accessible health offer for the entire population to resolve the situation. They must also intervene to develop the public transport network.

\section{Conclusions and Recommendations}

According to this study, we have concluded that a large part of the population of the city of Jeddah is located at a relatively high distance from a public clinic. The cartographic product helped us to discover the degree of inequalities in the distribution of public dispensaries, and allowed us to locate the favored population as well as the least favored.

To reduce this inequality between the different zones and districts of the city, the regional authorities must intervene by creating new dispensaries in several districts (Figure 15) and by strengthening the reception capacity of the other existing dispensaries. The creation and consolidation of a collective public transport network, which takes into account the issue of access to public dispensaries, can also help improve accessibility to these health centers.

The study of the cases of state dispensaries is insufficient to have a very precise idea of the health situation. Studying the structures and spatial distribution of state and private hospitals, private dispensaries and pharmacies is essential in order to have a clearer idea of the health situation in the city of Jeddah. The 


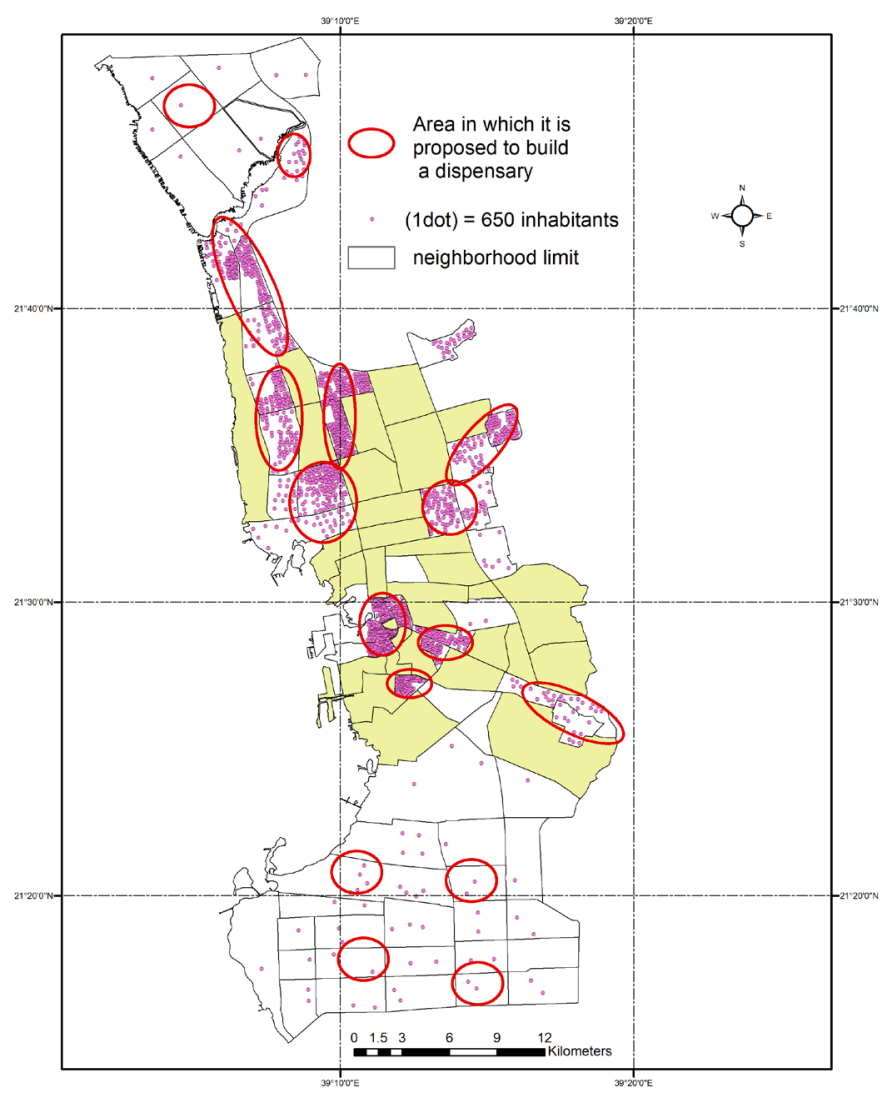

Figure 15. The areas proposed for the construction of public dispensaries in Jeddah.

study of all these health institutions requires much more time, resources and researchers. This may be the subject of another scientific project.

\section{Acknowledgements}

This project was funded by the Deanship of Scientific Research (DSR) at King Abdulaziz University, Jeddah, Kingdom of Saudi Arabia, under grant No. G-263-125-1440. The authors, therefore, acknowledge with thanks DSR for technical and financial support.

Dr. Mongi BELAREM, Principle-Investigator.

Dr. Mohamed Hafedh HAMZA, Co-Investigator.

Dr. Mohamed Ajmi, Co-Investigator.

\section{Conflicts of Interest}

The authors declare no conflicts of interest regarding the publication of this paper.

\section{References}

[1] Belarem, M., Hamza, M., Jamil, A. and Ajmi, M. (2018) Mapping and Analysis of the School Network of Makkah Al-Mukarramah (Saudi Arabia), Jeddah Girls' Secondary Schools as Example. Current Urban Studies, 6, 102-120. 
https://doi.org/10.4236/cus.2018.61005

[2] Bourgarel, S. Etchegaray, A. and Mazurek, H. (2017) Optimiser l'accès aux ressources sur les territoires dans un contexte contraint. Exemple des services de soins pour jeunes handicapés. Cybergeo. https://doi.org/10.4000/cybergeo.27902

[3] Picheral, H. (2001) Dictionnaire raisonné de géographie de la santé. Université de Montpellier, Montpellier, 3.

[4] Florence, J., Zeynep, O. and Engin, Y. (2019) Inégalités de recours aux soins en Europe: Quel rôle attribuable au système de santé?

http://www.ces-asso.org/docs/JESF_2007/jusot.pdf

[5] Német, G.F. and Bailey, A.J. (2000) Distance and Health Care Utilization among the Rural Elderly. Social Science \& Medicine, 50, 1197-1208. https://doi.org/10.1016/S0277-9536(99)00365-2

[6] Sabine, G., Simon, C., Jonathan, C. and Campbel Oona, M.R. (2011) The Influence of Distance and Level of Care on Delivery Place in Rural Zambia: A Study of Linked National Data in a Geographic Information System. PLOS Medicine, 8, e1000394. http://www.plosmedicine.org https://doi.org/10.1371/journal.pmed.1000394

[7] Ndonky, A., Oliveau, S., Lalou, R. and Dos Santos, S. (2015) Mesure de l'accessibilité géographique aux structures de santé dans l'agglomération de Dakar. Cybergeo: European Journal of Geography, document 751, mis en ligne le 07 décembre 2015, consulté le 22 août 2019. http://journals.openedition.org/cybergeo/27312 https://doi.org/10.4000/cybergeo.27312

[8] Potvin, L., Moquet, M.-J. and Jones, C. (2010) Réduire les inégalités sociales en santé. Saint-Denis: INPES, coll. Santé en action, 380 p.

[9] Niang, A. and Handschumacher, P. (1998) La desserte médicale et le recours aux soins de santé primaires dans le Delta du fleuve Sénégal. Evolution spatiale et temporelle, Editions de l'ORSTOM/Collection Colloques et Séminaires, 237-261.

[10] Mercier, A., Raux, C. and Avtracht, N. (2008) De la pertinence des mesures gravitaires de l'accessibilité: démonstration par la théorie et par l'exemple. International Conference on Mobility and Transport, 8-9 April 2008, 12 p. http://halshs.archives-ouvertes.fr/halshs-00283260/fr/

[11] Hansen, W.G. (1959) How Accessibility Shapes Land Use. Journal of the American Institute of Planners, 25, 73-76. https://doi.org/10.1080/01944365908978307

[12] Penchansky, R. and Thomas, J.W. (1981) The Concept of Access: Definition and Relationship to Consumer Satisfaction. Medical Care, 22, 127-140. https://doi.org/10.1097/00005650-198102000-00001

[13] Penchansky, R. and Thomas, J.W. (1984) Relating Satisfaction with Access to Utilization of Services. Medical Care, 19, 553-568. https://doi.org/10.1097/00005650-198406000-00006

[14] Joy, R. (2013) L'accès aux soins: Des perceptions du territoire aux initiatives des acteurs: Concepts, mesures et enquêtes pour une analyse géographique de l'organisation et du développement d'une offre de soins durable. Histoire. Université Paul Valéry -Montpellier III, 2013. Français

[15] Laurent, C. (2018) Accès aux soins: Eléments de cadrage. École nationale supérieure de Sécurité sociale, Regards, No. 53, 19-28. https://doi.org/10.3917/regar.053.0019 https://www.cairn.inforevue-regards-2018-1-page-19.htm

[16] https://www.moh.gov.sa

[17] https://www.jeddah.gov.sa 
[18] https://www.stats.gov.sa

[19] Ajmi, M., Hamza, M.H., Labiadh, M., Yermani, M., Ben Khatra, N., Al-Thubaiti, A.S., Moharrem, I.A. and El Arrim, A. (2014) Setting up a Spatial Data Infrastructure (SDI) for the ROSELT/OSS Network. Journal of Geographic Information System, 6, 150-161. https://doi.org/10.4236/jgis.2014.62016

[20] Al Sulami, M. (2010) La transformation socio-spatiale à Djeddah (Arabie saoudite). Thèse de doctorat en géographie, Université Paris IV, Sorbonne, 563 p.

[21] Al-Enazi, M. (2016) Traffic Congestion Evaluation Using GIS Case Study: Jeddah City. International Journal of Computer Applications, 138, 7-11.

http://www.ijcaonline.org/research/volume138/number1/alenazi-2016-ijca-908634. pdf https://doi.org/10.5120/ijca2016908634

[22] Aljoufie, M., Brussel, M., Zuidgeest, M. and Maarseveen, M.V. (2013) Urban Growth and Transport Infrastructure Interaction in Jeddah between 1980 and 2007. International Journal of Applied Earth Observation and Geoinformation, 21, 493-505. http://www.sciencedirect.com/science/article/pii/S0303243412001444 https://doi.org/10.1016/j.jag.2012.07.006

[23] Aljoufie, M., Zuidgeest, M., Brussel, M. and Maarseveen, M.V. (2013) Spatial-Temporal Analysis of Urban Growth and Transportation in Jeddah City, Saudi Arabia. Cities, 31, 57-68. https://doi.org/10.1016/j.cities.2012.04.008

[24] Aljoufie, M. (2014) Toward Integrated Land Use and Transport Planning in Fast-Growing Cities: The Case of Jeddah, Saudi Arabia. Habitat International, 41, 205-215. https://doi.org/10.1016/j.habitatint.2013.08.010

[25] Aljoufie, M. (2014) Spatial Analysis of the Potential Demand for Public Transport in the City of Jeddah, Saudi Arabia. In: Brebbia, C.A., Ed., Urban Transport $X X$, WIT Press, Southampton, 113-123. https://doi.org/10.2495/UT140101

[26] Baesse, S.S.O. (2012) Towards More Effective Urban Planning in Jeddah, Saudi Arabia. Doctoral Thesis of Philosophy in Urbain Planning, Melbourne, 304 p. https://researchbank.rmit.edu.au/eserv/rmit:161451/Baesse.pdf

[27] https://www.jeddah.gov.sa/Business/LocalPlanning/Atlas/index.php

[28] https://sgs.org.sa 